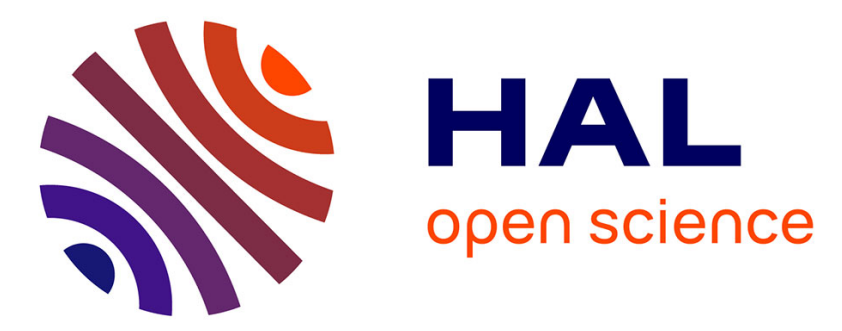

\title{
CNT Reinforced Light Metal Composites Produced by Melt Stirring and by High Pressure Die Casting
}

Qianqian Li, Christian A. Rottmair, Robert F. Singer

\section{To cite this version:}

Qianqian Li, Christian A. Rottmair, Robert F. Singer. CNT Reinforced Light Metal Composites Produced by Melt Stirring and by High Pressure Die Casting. Composites Science and Technology, 2010, 70 (16), pp.2242. 10.1016/j.compscitech.2010.05.024 . hal-00696564

\section{HAL Id: hal-00696564 https://hal.science/hal-00696564}

Submitted on 12 May 2012

HAL is a multi-disciplinary open access archive for the deposit and dissemination of scientific research documents, whether they are published or not. The documents may come from teaching and research institutions in France or abroad, or from public or private research centers.
L'archive ouverte pluridisciplinaire HAL, est destinée au dépôt et à la diffusion de documents scientifiques de niveau recherche, publiés ou non, émanant des établissements d'enseignement et de recherche français ou étrangers, des laboratoires publics ou privés. 


\section{Accepted Manuscript}

CNT Reinforced Light Metal Composites Produced by Melt Stirring and by High Pressure Die Casting

Qianqian Li, Christian A. Rottmair, Robert F. Singer

PII: S0266-3538(10)00220-4

DOI: 10.1016/j.compscitech.2010.05.024

Reference: CSTE 4729

To appear in: Composites Science and Technology

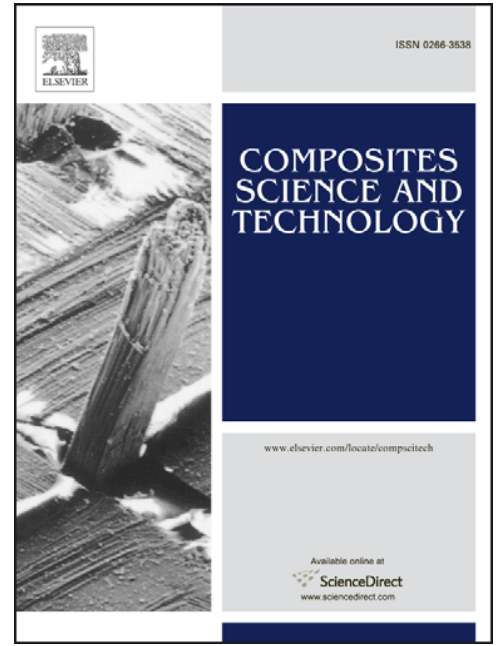

Received Date: $\quad 18$ November 2009

Revised Date: $\quad 3$ May 2010

Accepted Date: $\quad 26$ May 2010

Please cite this article as: Li, Q., Rottmair, C.A., Singer, R.F., CNT Reinforced Light Metal Composites Produced by Melt Stirring and by High Pressure Die Casting, Composites Science and Technology (2010), doi: 10.1016/ j.compscitech.2010.05.024

This is a PDF file of an unedited manuscript that has been accepted for publication. As a service to our customers we are providing this early version of the manuscript. The manuscript will undergo copyediting, typesetting, and review of the resulting proof before it is published in its final form. Please note that during the production process errors may be discovered which could affect the content, and all legal disclaimers that apply to the journal pertain. 


\title{
CNT Reinforced Light Metal Composites Produced by Melt Stirring and by High Pres- sure Die Casting
}

\author{
Qianqian Li, Christian A. Rottmair, Robert F. Singer \\ Institute of Advanced Materials and Processes, University of Erlangen-Nuremberg, \\ Dr.-Mack-Str. 81, 90762, Fuerth, Germany
}

\section{Abstract}

Light metal matrix composites are of great interest due to their potential for reducing $\mathrm{CO}_{2}$ emission through lightweight design e.g. in the automotive sector. Carbon nanotubes can be considered as ideal reinforcements, due to their high strength, high aspect ratio and thermomechanic properties. In this research, CNT reinforced light metal composites were produced by melt stirring and by high pressure die casting, which can be both easily scaled up. The light metal composites showed significantly improved mechanical properties already at small CNT contents. The influence of CNT concentration on the composites was also studied.

Keywords: A. Carbon nanotubes (CNTs); A. Metal-matrix composites (MMCs); A. Nano composites; B. Mechanical properties; E. Casting

\section{Introduction}

The issue of $\mathrm{CO}_{2}$ emission has become more and more critical during the last decades. One of the main sources of $\mathrm{CO}_{2}$ emission is from transportation. One liter of petrol consumption induces $2.34 \mathrm{~kg} \mathrm{CO}_{2}$ and the petrol consumption is directly connected to the average weight of a car. European Commission has proposed to reduce the average $\mathrm{CO}_{2}$ emission from new cars to $130 \mathrm{~g} / \mathrm{km}$ by 2012 , which means a requirement of 5.61 petrol / $100 \mathrm{~km}$ for a car. To fulfil this regulation, one of the solutions is to reduce the weight of a car. An average weight for a 
car of less than $800 \mathrm{~kg}$ is required. Therefore the use of light metals is becoming important. Currently lightweight metal alloys are used in relatively small quantities in automotive applications due to their relatively low strength which limits their potential applications. To overcome the limitations, much research has been done on producing light metal matrix composites to improve the mechanical properties by adding different reinforcements.

The reinforcing mechanisms considered to be most important in nano particle reinforced metal matrix composites are load transfer, Orowan mechanism and thermal mismatch. In order to obtain a high strengthening effect,

- Load transfer requires i) a high aspect ratio of the reinforcement ii) a much stronger reinforcement so the load can be efficiently transferred;

- Orowan mechanism requires a small interparticle spacing, i.e. for a certain volume fraction of the reinforcements, smaller particles yield smaller interparticle spacing as the number of particles increases; Additionally rod shaped reinforcements cause more strengthening compared to spherical reinforcements [1];

- Thermal mismatch needs a high difference of the coefficient of thermal expansion (CTE) between the reinforcements and the matrix to create higher dislocation density around the reinforcements.

To sum up, an ideal reinforcement to obtain a good strengthening effect in light metal matrix should have high strength, high aspect ratio, small diameter, a rod shape and a different CTE from light metal matrix, additionally with other good properties such as low density to keep the composites as light as their alloys. Accordingly carbon nanotubes (CNTs) can be considered as ideal reinforcements, due to their: favourable geometrical properties (high aspect ratio, high specific surface area), good physical properties and excellent mechanical properties. 
Theoretical simulation [2-5] and experimental results [6-9] have indicated their extraordinary strength (about $150 \mathrm{GPa}$ ) and Young's modulus (about $1 \mathrm{TPa}$ ).

The main reason for introducing CNTs into light metal matrix composites is enhancement of the mechanical properties but also the tailoring of density and hardness. Recent studies also mentioned the modified electrical conductivity, tribological and friction behaviour, and coefficient of thermal expansion. Because of the difficulties in introducing CNTs into metal melts, most work used powder metallurgical (PM) approaches [10-14] including hot pressing [1516], plasma spray forming [17-18] and hot extrusion [19-24]. Generally speaking, the property improvement achieved in CNT/metal composites fabricated by PM techniques has not fulfilled the expectations. This is commonly ascribed to the fact that CNTs are inhomogeneously dispersed and/or agglomerated at the grain boundaries of the metal matrix. A technology capable of dispersing CNTs homogenously in the metal melts is expected to overcome the problems listed above.

If few CNT are present, their reinforcing effect increases with increasing volume fraction. At elevated CNT volume fractions, homogeneous dispersion becomes difficult as CNTs begin to agglomerate. Hence, most research groups [25-27] pointed out that there is an optimum CNT volume fraction which produces maximum enhancement of mechanical properties.

In this work, carbon nanotube reinforced light metal composites were produced by two different methods. One is to produce CNT reinforced Mg AZ91 composites by a two-step process, which has been described in our previous papers [28-29]. The two-step process includes: step one is a pre-dispersing procedure of CNTs on the $\mathrm{Mg}$, in order to break down big agglomerates; step two is the fabrication of CNT/Mg alloy composite by a melt stirring technique. At step one a block copolymer is used as a dispersing agent to pre-disperse CNTs on Mg alloy chips. The block copolymer was chosen because it has already been proven in previous re- 
search that it can improve the dispersion of CNT in ethanol [30-31]. In our previous paper, we have already shown that by adding a small amount of CNTs $(0.1 \mathrm{wt} \%)$, the mechanical properties of the composites have been improved. In this paper, we continue our research and use different amount of CNTs to produce the Mg composites.

Another method is to produce CNT reinforced Al alloy composites by high pressure die casting process. High pressure die casting is an efficient and economic process manufacturing complex shaped components in high quantities. Furthermore, the high-speed casting process provides a high sheer speed to disperse carbon nanotubes homogenously into the $\mathrm{Al}$ alloy melt. In this paper, we introduce high pressure die casting to produce CNT/Al alloy composites and investigate the resulting enhancement of mechanical properties.

\section{Experimental}

\subsection{Melt stirring}

The block copolymer Disperbyk-2150 (BYK Chemie GmbH) was first dissolved in ethanol in a small beaker. Then multiwall CNTs (MWNTs, mass ratio to the block copolymer 1:1, Baytubes $\left.{ }^{\circledR} \mathrm{C} 150 \mathrm{P}\right)$ were added to the as-prepared solution. This mixture was put at roomtemperature into an ultrasonic bath for 15 minutes. Then it was stirred for 30 minutes at 250 rpm. After adding Mg alloy chips (AZ91 D, ECKA), the suspension was further stirred at 250 rpm inside a fume cupboard to evaporate ethanol and homogenize the mixture. After the mixture was dried, the MWNT coated chips were placed in a cylindrical sample crucible as show in Figure 1 [28]. This crucible was placed into an oven used in our previous paper and heated up to $670^{\circ} \mathrm{C}$ under an inert gas atmosphere to avoid oxidation. When the $\mathrm{Mg}$ alloy chips were molten, the liquid was mechanically stirred at $350 \mathrm{rpm}$ for 30 minutes to further disperse MWNTs. After stirring, the molten MWNT/Mg composite was poured into a mould. The 
cooled sample was machined to cylindrical shaped specimens (diameter $5 \mathrm{~mm} \times$ height $7 \mathrm{~mm}$ ) for subsequent compression tests. According to the described procedure, AZ91 composites with different contents of MWNTs $(0.1 \mathrm{wt} \%, 0.5 \mathrm{wt} \%$ and $1 \mathrm{wt} \%)$ were produced. Reference samples were made using exactly the same procedure but from pure AZ91.

After the pre-dispersion step scanning electron microscopy (SEM) was used to observe the microstructure on the surface of CNT coated Mg chips. The resulting samples were tested by compression testing to determine the compression at failure, compressive yield strength and ultimate compressive strength. Tests were conducted at ambient temperature using standard tensile/compression testing equipment (100 kN load cell). Testing was performed at a constant strain rate of 0.01 second $^{-1}$.

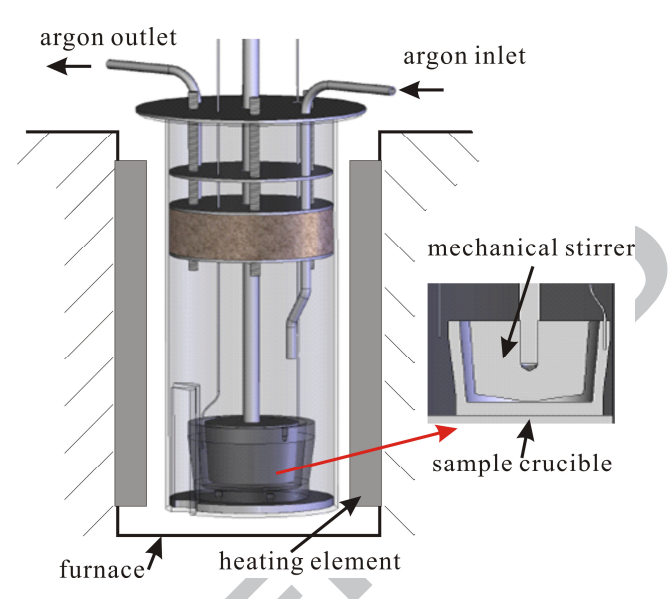

Figure 1. Melt stirring equipment [28]

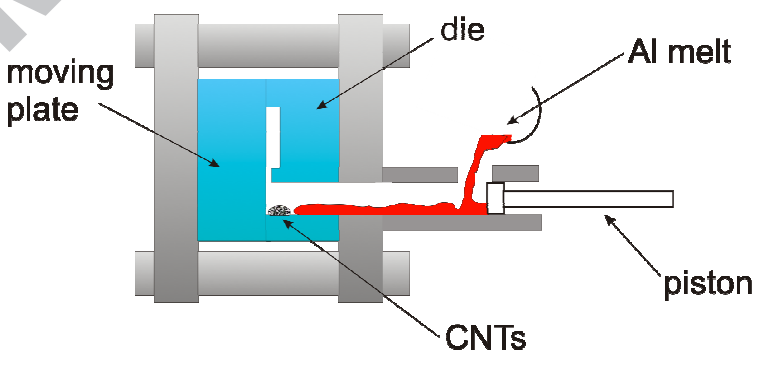

Figure 2. High pressure die casting

\subsection{High pressure die casting}

MWNTs (0.05 wt\%, Baytubes® C 150P) were weighted and then wrapped in Al foil to form a ball. Four balls containing MWNTs were set on the entrance of the die as shown in Figure 2. The molten Al alloy (A1239D, AlSi10Mg) was pushed into the die by the piston with a high velocity. Because of the small cross section at the entrance, the melt is accelerated to a high speed (as fast as $250 \mathrm{~m} / \mathrm{s}$ ), which leads to a turbulent flow in the die and could help the dis- 
persion of MWNTs [32]. After cooling, the samples were cut to dog-bone shapes for tensile testing. Tests were conducted at ambient temperature using standard testing equipment (Instron $4505,100 \mathrm{kN})$. Testing was performed at a constant cross-head speed of $5 \mathrm{~mm} / \mathrm{second}$. X-ray diffraction (XRD, Philips X'Pert)) was conducted on the pure Al alloy and the MWNT reinforced $\mathrm{Al}$ alloy to check for carbide formation in the composites.

\section{Results and Discussion}

\subsection{Melt stirring}

For Step 1, the pre-dispersion of CNTs on the Mg alloy chips, SEM analysis was used to study the microstructure of the raw MWNTs and the MWNT coated Mg alloy chips. Figure 3 (a) and (b) are SEM images of the MWNTs as received. From the images, it can be observed clearly that the raw MWNTs are agglomerated in big bundles. Figure 3 (c)-(f) exhibit the SEM images of dispersed MWNTs on Mg alloy chips. Individual MWNTs can be found on the $\mathrm{Mg}$ surface after the pre-dispersion process. In the case of $0.1 \mathrm{wt} \%$ and $0.5 \mathrm{wt} \%$ of MWNTs, no agglomerates can be observed. When increasing the amount of MWNTs, agglomerates of entangled MWNTs with a size of up to $2 \mu \mathrm{m}$ can be observed (Figure $3 \mathrm{f}$ ). Therefore, we can conclude that for a small amount of MWNTs, during step one, MWNTs can be homogenously dispersed on the Mg chips. For the samples with increased amount of MWNTs, agglomerates can still be found. 

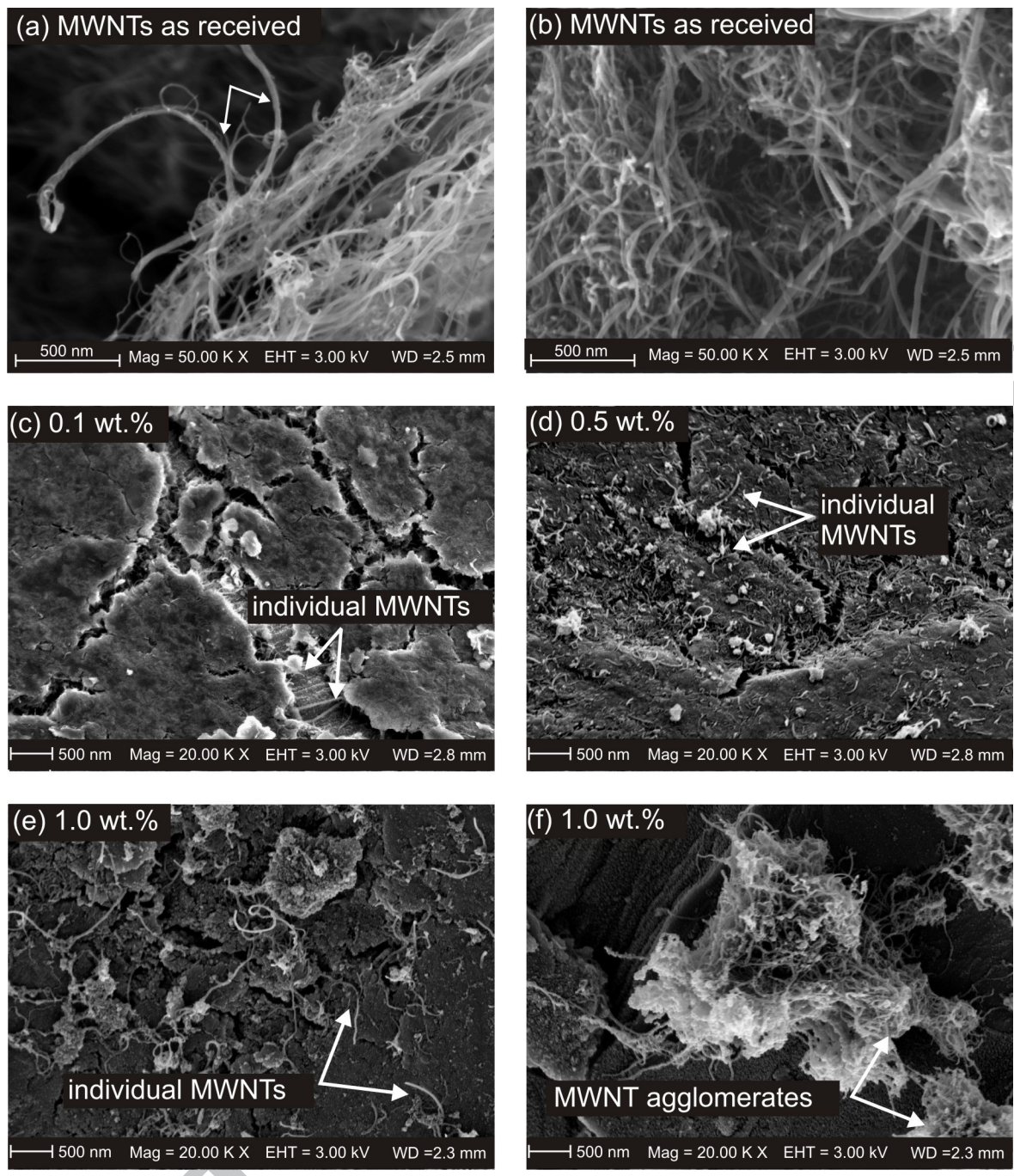

Figure 3. . SEM images of (a), (b) raw MWNTs as received; (c-e) MWNTs dispersed on the surface of the AZ91 chips, where different nominal amounts of MWNTs were added. (f) With increasing weight fraction of MWNTs larger agglomerates can be observed, which are non-existent in the case of the $0.1 \mathrm{wt} \%$ and $0.5 \mathrm{wt} \%$ MWNT/AZ91 chips.

For the MWNT reinforced AZ91 composites, mechanical properties were measured by compression test. Typical stress-strain curves of the different MWNT/Mg composite and the pure AZ91 Mg alloy are shown in Figure 4 (a). It is clear that the compression at failure and the ultimate compressive strength were all increased by addition of MWNTs. There is no obvious change of compressive yield strength. And it can be seen that the mechanical properties for 
the MWNT/AZ91 composites do not change significantly with an increasing amount of

\section{MWNTs.}

To improve the statistical significance of the results, 24 specimens were tested following the same procedure. The properties for the composites are shown in Figure 4(b)-(d), as a function of weight fraction of MWNTs. The properties of the AZ91 are also plotted for comparison.
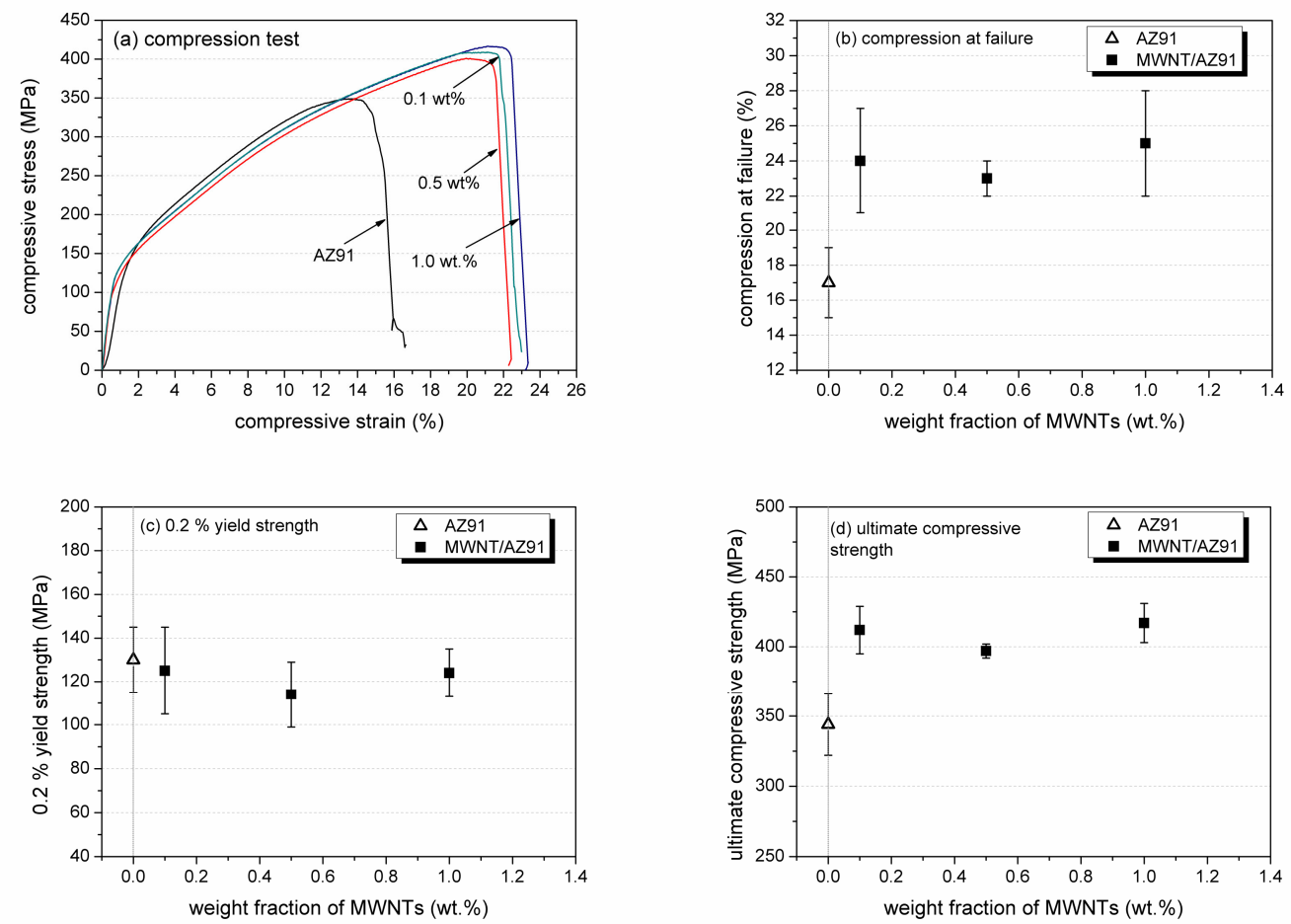

Figure 4. (a) Typical compression stress-strain curves of different MWNT AZ91 alloy composites (0.1 wt.\%, 0.5 wt. $\%$ and 1 wt. $\%$ ) and AZ91. Comparison of (b) compression at failure; (c) $0.2 \%$ yield strength and (d) ultimate compressive strength averaged over 24 samples.

The compression at failure and the ultimate compressive strength increases significantly for the MWNT/AZ91 composites compared to the AZ91 alloy by adding a small amount of CNTs, as discussed in our previous paper [29]. An increase of the ultimate compressive strength of $20 \%$ has been reached by adding $0.1 \mathrm{wt} \%$ MWNTs. An even higher increase was 
observed for the compression at failure of the MWNT/AZ91 composites, which increased about $40 \%$ compared to the AZ91. The improvement of the mechanical properties of the composites is contributed to excellent properties of carbon nanotubes. Moreover, combining the SEM observation with the results of our mechanical testing, we attribute the improvement of the mechanical properties to the good dispersion of MWNTs in the Mg metal matrix.

Compared to AZ91, adding MWNTs did not change the $0.2 \%$ yield strength as dramatically as other properties. The value of the $0.2 \%$ yield strength for AZ91 is $130 \mathrm{MPa}$. For the $0.1 \mathrm{wt} \% \mathrm{MWNT} / \mathrm{AZ} 91$ composite, the $0.2 \%$ yield strength is $125 \mathrm{MPa}$ and does not significantly change by increasing the amount of MWNTs, regarding the scattering of the data. However, because of the limitation of the measured sample geometry, i.e. the top surface of the cylinder sample was not perfectly parallel to the bottom surface, and the short gauge length ( $7 \mathrm{~mm}$ in the case) in the compression test, the $0.2 \%$ yield strength may not be very accurate. $1 \%$ or $2 \%$ yield strength will be measured for comparison in our further study. When increasing the amount of the MWNTs, there was no obvious effect on the mechanical properties. This can be explained by the fabrication process. It has been observed that with an increasing amount of MWNTs, not all MWNTs could be separated into individual MWNTs during the pre-dispersion process (see Figure 3). Larger agglomerates may be incorporated into the composite. Hence, the mechanical properties remain the same when increasing the amount of MWNTs, as the large agglomerates do not enhance the properties of the resulting composites.

Furthermore, during the experiments it could be observed that by increasing the amount of MWNTs, a larger amount separated to the top or bottom of the melt and did not reside in the melt. Therefore it could be possible that the real amount of MWNTs embedded in the com- 
posites is similar for the nominal $0.1,0.5$ and $1.0 \mathrm{wt} . \%$ MWNT reinforced composites. As a result, the mechanical properties are similar for all the composites.

\subsection{High pressure die casting}

Figure 5(a) shows typical stress-strain curves of the MWNT/Al alloy composites and the pure $\mathrm{Al}$ alloys. It is clear that the tensile stress and the elongation at fracture were both increased by addition of only $0.05 \mathrm{wt} \%$ MWNTs. To obtain accurate results, 14 samples were tested following the same procedure. The results are complied in Figure 5(b) and (c). By adding only $0.05 \mathrm{wt} \%$ of MWNTs, the elongation at fracture has increased $27 \%$ compared to pure Al alloy; the tensile strength of CNT/Al composites increased $8 \%$ compared to pure $\mathrm{Al}$ alloy. Especially the elongation at fracture has also increased together with the tensile strength, which is different from by using traditional reinforcements such as carbon fibres [33].
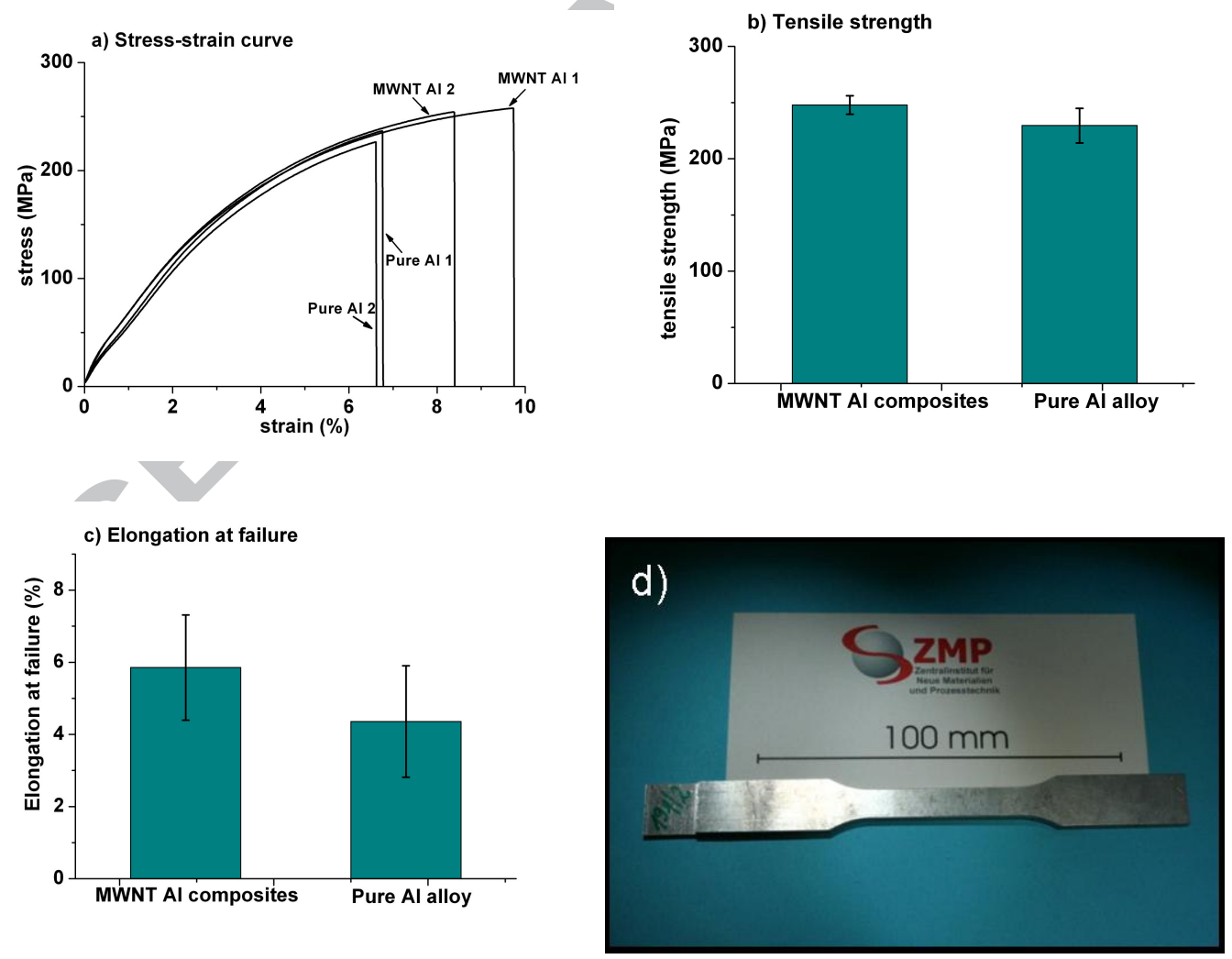
Figure 5. (a) Typical tensile stress-strain curves of MWNT Al composites (two samples) and pure Al alloy (two samples). Comparison of (b) elongation at fracture and (c) tensile strength as average of obtained 14 samples. (d) dog-bone shaped sample.

In order to check for carbide formation in our composites XRD measurements were conducted on pure Al alloy and the MWNT/Al composites [34]. As can be seen in Figure 6, the XRD results of $\mathrm{Al}$ alloy and MWNT/Al composites show complete overlapping. The intensity of the $\mathrm{Al}$ and $\mathrm{Si}$ peaks shows also no changes. The results indicate that there is no carbide formation in our MWNT/Al composites, which may be due to the low content of CNTs (only $0.05 \mathrm{wt} \%)$ in the composites. It can be also explained that in our die casting process, the $\mathrm{Al}$ melt has only limited contact time with the CNTs at high temperature (several seconds) before the composite solidifies in the relatively cold die $\left(200^{\circ} \mathrm{C}\right)$.

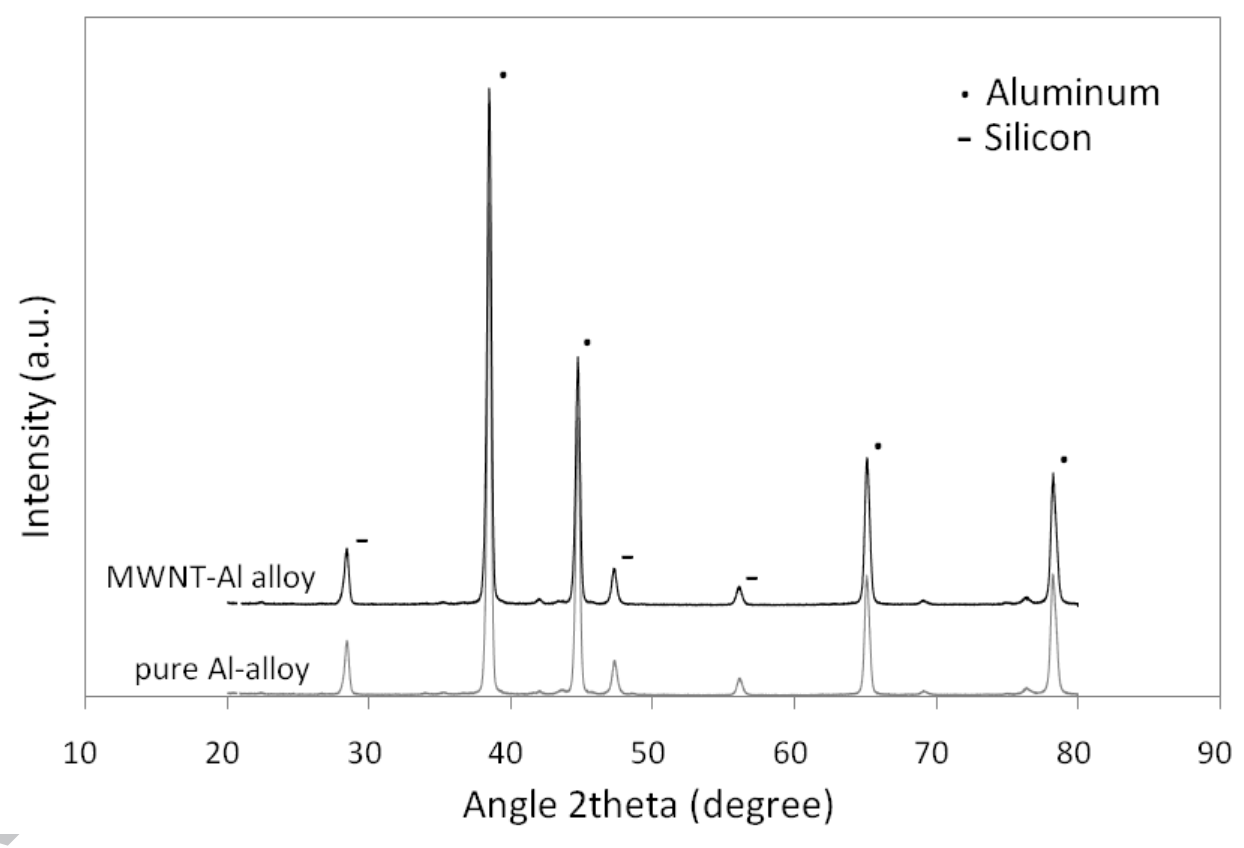

Figure 6. XRD scans of pure $\mathrm{Al}$ alloy and MWNT-Al alloy.

The lack of carbide formation indicates that the enhanced mechanical properties of the composite can be attributed to the added carbon nanotubes. In the future further characterisation by scanning electron microscopy and transmission electron microscopy would be desirable. 
Combining the mechanical property improvements and the XRD results, we attribute the enhancement of all mechanical properties to the advanced mechanical properties of the carbon nanotubes.

\section{Conclusions}

In this study, CNT reinforced light metal composites were produced successfully by two different methods: melt stirring and high pressure die casting. It demonstrated that CNT reinforced light metal composites can be produced by straight-forward procedures that can be easily scaled up for industrial applications. These composites hold great potential for the use in lightweight construction and through this for the reduction of $\mathrm{CO}_{2}$ emission in areas like transportation.

By adding only a small amount of CNTs, the mechanical properties of the light metal matrix composites have all been improved. For the melt stirring method, research was carried out following our previous study [27]. Compared to the AZ91 Mg alloy, the compression at failure of the MWNT/Mg composites could be improved up to $40 \%$ and the ultimate compressive strength could be improved up to $20 \%$. For high pressure die casting, tensile testing showed that by adding only $0.05 \mathrm{wt} \%$ of MWNTs, the elongation at fracture has increased by $27 \%$ compared to pure $\mathrm{Al}$ alloy and the tensile strength of $\mathrm{CNT} / \mathrm{Al}$ composites increased $8 \%$ compared to pure $\mathrm{Al}$ alloy. $\mathrm{XRD}$ results indicate that there is no carbide formation in our CNT/Al composites. We attribute the improvement of the mechanical properties to the excellent properties of CNTs and relatively good dispersion of CNTs in the Mg matrix.

However, no obvious change was found for different amounts of MWNTs. This can be explained by agglomerates still existing in composites of high MWNT content and the difference between embedded amount of MWNTs in the composites and the nominal amount due 
to the process limitations. It indicates the importance of improving dispersability and wettability of the CNTs in the matrix.

\section{Acknowledgements}

A financial grant of the Bavarian State Ministry of Science is gratefully acknowledged. We would like to thank Christian Rauber, Natalie Kömpel, Jens Schaufler, Matthias Rübner, Jörg Komma and Sergiu P. Albu for their kind technical assistant. We are indebted to Bayer AG, BYK Chemie GmbH and ECKA Granulate GmbH \& Co. KG. for their generous offers of the materials used in this study. We greatly appreciate Dr. Jan Schwerdtfeger for fruitful discussions and suggestions.

\section{References}

[1] Kelly PM. Scripta Metallurgica 1972; 6: 647-656.

[2] Yao Z, Zhu CC, Cheng M, Liu J. Comp Mater Sci 2001; 22: 180-184.

[3] Wu Y, Zhang X, Leung AYT, Zhong W. Thin-Walled Structure 2006; 44: 667-676.

[4] Li C, Chou T. Int J Solids and Structure 2003; 40: 2487-2499.

[5] Ru C. Phys Rev B 2000; 62:9973-76.

[6] Treacy MMJ, Ebbesen TW, Gibson JM. Nature (London) 1996; 381(6584): 678-680.

[7] Yao N, Lordi V. J App Phys 1998; 84: 1939-1943.

[8] Wong E, Sheehan P, Lieber C. Science 1997; 277 (5334): 1971-1975.

[9] Yu MF, Lourie O, Dyer MJ, Moloni K, Kelly TF, Ruoff RS. Science 2000; 287 (5453): 637-640.

[10] George R, Kashyap KT, Rahul R, Yamdagni S. Strengthening Scripta Mater 2005; 53: 1159-1163. 
[11] Xu CL, Wei BQ, Ma RZ, Liang J, Ma XK, Wu DH. Carbon 1999; 37: 855-858.

[12] Peigney A, Rul S, Lef evre-Schlick F, Laurent C. J. European Ceramic Society 2007; 27: 2183-2193.

[13] Goh CS, Wei J, Lee LC, Gupta M. Nanotechnology 2006; 17: 7-12.

[14] Esawi A, Morsi K, Sayed A, Abdel Gawad A, Borah P. Mater Sci Eng A 2009; 508: 167173.

[15] Carreno-Morelli E, Yang J, Couteau E, Hernadi K, Seo JW, Bonjour C, Forró L, Schaller R.Phys.Stat. Sol.2004; 210:R53-55.

[16] Laha T, Kuchibhatla S, Seal S, Li W, Agarwa A. Acta Mater 2007; 55: 1059-1066.

[17] Deng CF, Wang DZ, Zhang XX, Li AB. Mater Sci Eng A 2007; 444: 138-145.

[18] Bakshi SR, Singh V, Seal S, Agarwa A. Surface \& Coatings Technology 2009; 203: $1544-54$

[19] Choi HJ, Kwon GB, Lee GY, Bae DH. Scripta Mater 2008; 59: 360-363.

[20] Pérez-Bustamante R, Gómez-Esparza CD, Estrada-Guel I, Miki-Yoshida M, LiceaJiménez L, Pérez-García SA, Martínez-Sánchez R. Mater Sci Eng A 2009; 502: 159-163.

[21] Kwon H, Estili M, Takagi K, Miyazaki T, Kawasaki A. Carbon 2009; 47: 570-577.

[22] Goh CS, Wei J, Lee LC, Gupta M. Mater Sci Eng A 2006; 423: 153-6.

[23] Shimizu Y, Miki S, Soga T, Itoh I. Scripta Mater 2008; 58: 267-70.

[24] Thakur SK, Srivatsan TS, Gupta M. Mater Sci Eng A 2007; 466: 32-37.

[25] Esawi AMK, Borady MAE. Carbon nanotube-reinforced aluminium strips. Comp Sci Tech 2008; 68: 486-92.

[26] Deng CF, Ma YX, Zhang P, Zhang XX, Wang DZ. Thermal expansion behaviors of aluminum composite reinforced with carbon nanotubes. Mater Lett 2008; 62: 2301-3. 
[27] Zhou S, Zhang X, Ding Z, Min C, Xu G, Zhu W. Fabrication and tribological properties of carbon nanotubes reinforced $\mathrm{Al}$ composites prepared by pressureless infiltration technique. Composites: A 2007; 38: 301-6.

[28] Li Q, Viereckl A, Rottmair CA, Singer RF. Comp Sci Tech 2009; 69: 1993-1999.

[29] Li Q, Rottmair CA, Singer RF. In: K. U. Kainer (Ed.), Magnesium: 8th International Conference on Magnesium Alloys and their Applications 2009; p661-666.

[30] Li Q, Zaiser M, Koutsos V. Physica Status Solidi A 2004; 201(13): R89-R91.

[31] Bright I, Koutsos V, Li Q, Cheung R. Microelectronic Engineering 2006; 83(4-9): 15426.

[32] Ruebner M, Koerner C, Singer RF. Adv. in Sci. Tech. 2008; 56: 170-175.

[33] Daoud A. Materials Science and Engineering A. 2005. 391: 114-120.

[34] Ci L, Ryu Z, Jin-Philipp N, Ruehle M. Acta Materialia 2006. 54: 5367-75. 


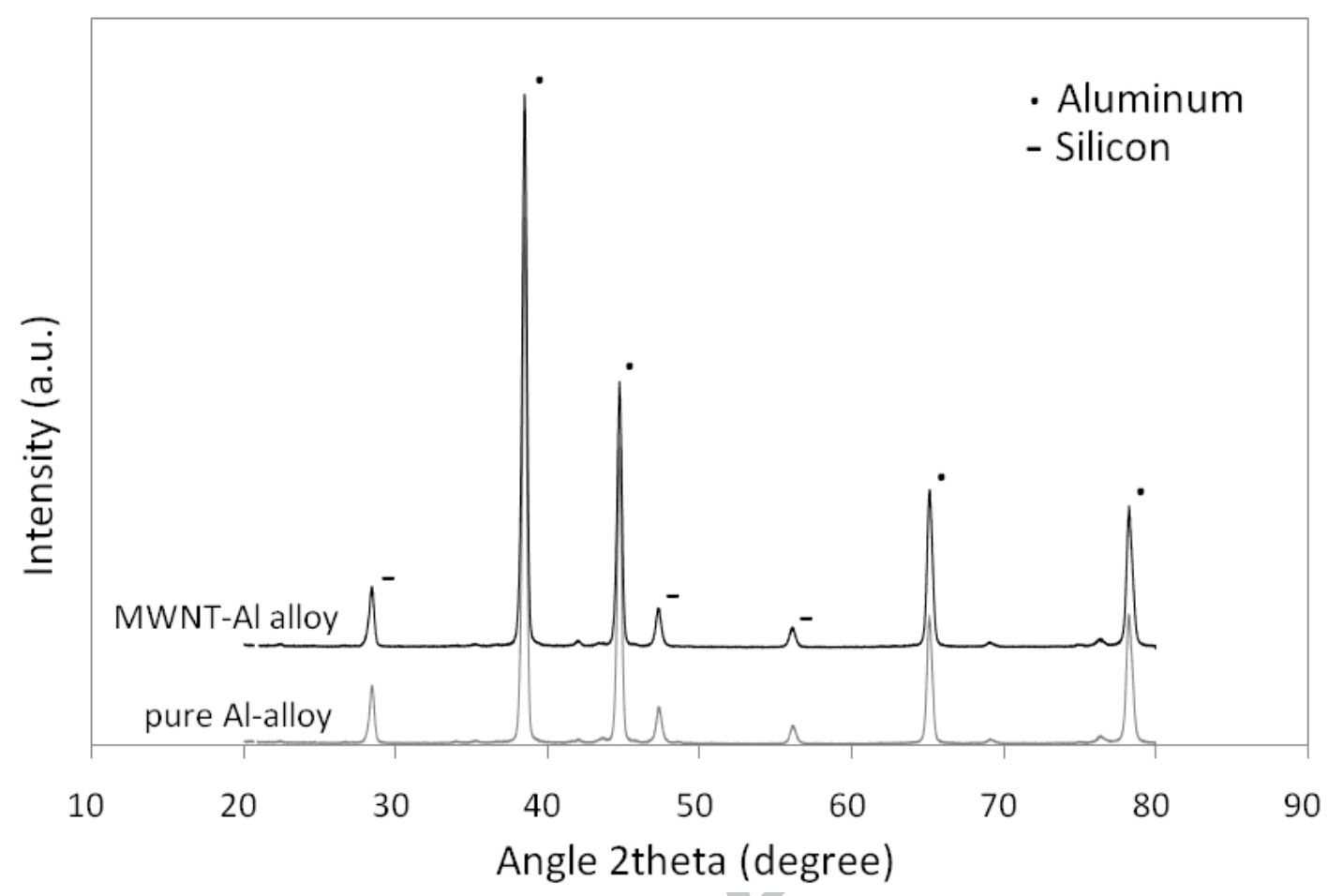

